\title{
A Comparative Analysis of the Parameters of "Hardiness" and "Resilience"
}

\author{
Elena Ivanovna Nikolaeva
}

\section{Oksana Evgen'evna Elnikova}

Department of Psychophysiology and Pedagogical Psychology, Institute of Psychology and Pedagogics, Yelets State Bunin University, 28 Kommunarov Str., Yelets, Lipetsk Region, 399770, Russian Federation; E-mail: klemtina@yandex.ru

\section{Doi:10.5901/mjss.2015.v6n5s4p219}

\section{Abstract}

The article presents a psychophysiological analysis of the resilience and hardiness of the adult tested persons (68 people). The tested persons were divided into three groups in accordance with the objective health indicators. The resilience of adults with chronic diseases is associated with the ability to predict the pattern of the signal input in a complex sensorimotor response. The hardiness is not associated with the psychophysiological characteristics. However, it is correlated with the coping strategies of "problem solving" and "coping focused on emotions", as well as with the self-assessment of health. The tested persons with chronic diseases, as opposed to the tested persons without chronic diseases, better predicted the pattern of the sensory input of signals in a complex sensorimotor response, which is estimated by the authors as a manifestation of the resilience. It is concluded that the resilience and hardiness not only have a different result for a person after overcoming a difficult situation, but also possess different mechanisms of occurrence.

Keywords: resilience, hardiness, simple and complex sensorimotor response, heart rate variability, fractal input of signals.

\section{Introduction}

The complexity of describing the quality of human life is primarily associated with the objective difficulties in selecting the adequate methods of assessment (Ware and Sherbourne, 1992). The evolutionary mechanism, formed back in the days when people actively fought for survival within the changing environment, does not allow them to experience durably the state of happiness or well-being. The memory of negative events remains in the human mind for a long time, whereas the pleasure of achievements are quickly replaced by new concerns and challenges (Nikolaeva and Elnikova, 2014). That is why any welfare-related matter is of extremely acute dependence on the immediate attitudes rather than on the durable states.

The quality of life is studied through the investigation of external parameters (health, education, success, etc.) or with due regard to the internal indicators such as satisfaction with life, family, job, etc.

At different life stages, a person faces difficult circumstances, which can be overcome with different results. For this purpose, the current literature provides two fundamentally different concepts-resilience and hardiness.

\section{Literature Review}

Hardiness is a system of beliefs of oneself, of the world, and of the relations with the world. This is a disposition that includes three relatively independent components: the involvement, the control, and the risk acceptance. The intensity of these components and of hardiness as a whole prevents the emergence of internal tension in stressful situations due to the hardycoping with stresses and the perception thereof as less important ones (Maddi et al., 2006).

Hardiness characterizes the measure of the individual's ability of withstanding a stressful situation while maintaining the internal balance and not reducing the success of activity (Ngo-Metzger et al., 2008).

Resilience moderates the impact of negative factors on the human health (Windle et al., 2010). This characteristic describes the ability of withstanding difficult circumstances of the environment, so that in the process of overcoming the obstacles, a person acquires new qualities that could have hardly been generated if these negative conditions had not been experienced. The efficiency of this result presents the psychologists with the question, under which conditions a person not just overcomes the difficult circumstances, but also, in the process of overcoming thereof, acquires the new positive qualities. 
One of the most difficult situations, in which any adult can appear, is the development of a chronic disease. The objection for the analysis of such a situation herein may be the fact that the disease is more likely to occur in people with a lower level of resilience. This is true, but the very fact of obtaining the knowledge on that there is a chronic disease, which will protract for an indefinite period of time, of course, causes in people various behavioral responses, which in turn may increase the human resource in the process of solving the newly arisen problem or, conversely, reduce the former (Endler et al., 1994).

There is a repeatedly tested questionnaire used for the analysis of hardiness (Leont'ev and Rasskazova, 2006). But how to assess resilience, which is the acquisition by a person of the quality that could have hardly occurred if a person had not got into a difficult situation?

Both the experiencing of a disease and the staying in the natural environment are related to the analysis of the information that is transmitted into the brain. The efficiency of the analysis allows for the planning of various predictive values. From this perspective, the ability to determine the pattern of the sensory input can be an important human psychophysiological resource in the process of overcoming difficult situations. That is why the purpose of this part of the study was to analyze the ability of describing the pattern of the sensory input by the subjects with different perception of their health.

\section{Methods and Materials}

All the tested persons gave consent for the study of their medical records, which included the results of the annual medical examinations by many specialists. In accordance with the results obtained, the tested persons were divided into three groups: the first group included the healthy subjects (no relevant entries in medical records and no subjective health complaints from the subjects, 15 people); the second group included the subjects that for the first time experienced or felt certain symptoms of a disease that proved to be temporary, and in the medical records, there were no entries of any chronic disease (23 people); the third group included subjects with chronic diseases, the occurrence of which was committed by physicians to the medical records ( 30 people).

We understand that this division of subjects is relative and that there are diseases that for a certain period can proceed without symptoms, as well as that there are evidences of spontaneous curing of chronic diseases. However, the task is to find signs of resilience, that is, the ability of acquiring additional qualities in overcoming the problem is related not to a real disease, but to what degree a person is aware thereof and how he perceives the difficulty of overcoming the situation occurred. Furthermore, we understand that very often the annual medical examinations are carried out quite formally. However, the availability of statistical processing in our study may reduce the number of errors associated with the inaccuracy of diagnostics.

The following parameters were evaluated. The features of hardiness with the help of the Maddi's questionnaire (Maddi and Harvey, 2005) adapted by Leont'ev (Leont'ev and Rasskazova, 2006); the quality of life was assessed using the "SF-36 Health Status Survey"(Windle et al., 2010). The Russian translation and the methodology testing were provided by the Institute of Clinical and Pharmacological Studies (St. Petersburg). 36 issues of the questionnaire were grouped into eight scales: General Health $(\mathrm{GH})$-the subject's currently perceived health status; Physical Functioning (PF)-reflects the extent, in which the health limits the performance of physical activities; Role-Physical (RP)—-the physical state effect on the role functioning; Role-Emotional (RE) - the emotional state effect on the role functioning that involves assessing the extent, in which the emotional state obstructs the job performance or any other daily activity; Social Functioning (SF) -is determined by the extent, in which the physical or emotional state limits the social activity; Bodily Pain (BP)-the intensity of pain and its impact on the ability of being engaged in daily activities including the household chores and work outside the house; Vitality (VT) — the indicator of resilience; Mental Health (MH)—-the selfassessment of mental health that characterizes the mood.

Besides, the coping strategies in stressful situations were described by Norman, Endler, James, and Parker, adapted by Kriukova (Norman et al., 2002). The methodology describes the dominant coping strategies in stressful situations. The questionnaire was prepared in the form of a list of defined responses to stressful situations, of which a subject chooses the ones that he most frequently uses in real life. This variant of testing describes the coping focused on solving problem situations, the coping focused on the emotions, and the coping associated with the strategy of avoidance.

The questionnaire was prepared in the form of a list of defined responses to stressful situations, of which a subject chooses the ones that he most frequently uses in real life. In accordance with the questionnaire, the coping strategies are classified into the coping focused on solving a problem situation, the coping focused on the emotions, and the strategy of avoidance. The integrated use of these methodologies makes it possible not only to assess the psychoemotional state, 
but also to determine how constructive the coping strategy, which an individual chooses, is.

We further assessed the parameters of both the simple and complex sensorimotor response using the ReBOS methodology (Nikolaeva et al., 2015). At first, a training series was conducted, which was a simple sensorimotor response, but differed from the first series in that it had a different input pattern of the signal and was intended to familiarize a subject with the program.

A simple sensorimotor response was considered as the most rapid human response to the known in advance stimulus in the known in advance manner (in this experimental study, it is manifested through pressing the space bar each time a circle appears in the first series of the methodology performance). A complex sensorimotor reaction is the complication of the response aimed at the analysis of inhibitory processes in the central nervous system associated with the requirement not to click on a circle of a certain color.

The procedure of a simple sensorimotor response was performed in the series comprising two identical parts (not known to the subject), with the help of which the ability of learning in the first part of the series, and of unconsciously more accurate responding to stimuli in the second part was assessed. An analysis of the data obtained in the course of registering the sensorimotor response of the subjects was executed according to the following parameters: the stimulus omissions; the errors (a subject violates the instructions in a complex sensorimotor response by clicking on a prohibited stimulus); and the average number of errors.

In each half of the series, the $\Delta$ indicator was estimated as a result of subtracting $\mathrm{Hx}$ (the Hurst exponent of the subject's response) from Hy (the Hurst exponent of the input of signals in the program) taken in absolute value, which indicates the extent, to which the actions of a subject deviate in time from the real time of the stimulus onset.

Since each series consisted of two iterating inputs of signals, it became possible to assess the person's ability to unconsciously notice this regularity and predict the emergence of the next stimulus. This ability of predicting could be assessed by comparing the values of $\Delta 1$ of the first half of the series and of $\Delta 2$ of the second half of the series. The result of the comparison was the $\Omega$ parameter that assessed the difference between $\Delta 1$ and $\Delta 2$. If the value $\Delta 2$ was less than $\Delta 1$, then a person could unconsciously detect the fact that the second half of the series was a complete repetition of the first one, and therefore it more accurately reproduced the fractal sequence of stimuli emergence in the second part of the series than in the first one.

\section{Results and Discussions}

At first, we described the parameters of hardiness of the tested persons of different groups, and calculated the cumulative hardiness. It turned out that the difference between the groups was detected only by one indicator - the risk acceptance (Table 1). Wherein, as might be expected, the risk is the most easily accepted by the healthy people, and the less easily - by those, who felt the symptoms of a disease by the first time.

Table 1. The psychological indicators of subjects of three groups (the mean and standard deviation, scores)

\begin{tabular}{|c|c|c|c|c|}
\hline \multirow{2}{*}{ Health groups } & \multicolumn{3}{|c|}{ Indicators } \\
\cline { 2 - 5 } & Involvement & Control & Risk acceptance & Hardiness \\
\hline 1 & $39.1 \pm 5.9$ & $29.9 \pm 7.2$ & $20.1 \pm 4.1$ & $90.3 \pm 11.4$ \\
\hline 2 & $37.7 \pm 9.2$ & $29.4 \pm 7.2$ & $15.6 \pm 5.5^{\star}$ & $82.7 \pm 20.1$ \\
\hline 3 & $39.6 \pm 7.4$ & $30.9 \pm 12.2$ & $16.8 \pm 5.3$ & $87.0 \pm 22.9$ \\
\hline
\end{tabular}

Note:* - the differences of data of the corresponding group from the data of the first group with the significance value of $p \leq 0.05 ;{ }^{*}-p \leq 0.01$ (the Wilcoxon test).

Further, we assessed the differences between the groups according to the other studied parameters (Table 2).

Table 2. The psychological indicators of subjects of three groups (The mean and standard deviation, scores)

\begin{tabular}{|c|c|c|c|c|c|}
\hline \multirow{2}{*}{ Health groups } & \multicolumn{4}{|c|}{ Indicators } \\
\cline { 2 - 6 } & Internality in the sphere of health & Level of general internality & Emotional coping & Anxiety & Self-assessment of health \\
\hline 1 & $5.0 \pm 1.2$ & $24.9 \pm 5.5$ & $38.6 \pm 10.1$ & $0.55 \pm 0.63$ & $87.1 \pm 84$ \\
\hline 2 & $5.2 \pm 1.3$ & $23.3 \pm 5.5$ & $42.8 \pm 11.8$ & $1.01 \pm 0.71^{\star}$ & $65.6 \pm 11.5^{\star}$ \\
\hline 3 & $6.1 \pm 1.3^{*}$ & $27.8 \pm 4.9^{*}$ & $46.8 \pm 8.1^{*}$ & $0.60 \pm 0.44$ & $69.9 \pm 8.2$ \\
\hline
\end{tabular}

Note:* - the differences of data of the corresponding group from the data of the first group with the significance value of $p \leq 0.05$; ** $-p \leq 0.01$ (the Wilcoxon test). 
The data indicate the significant differences between the groups in all parameters. The subjects quite clearly assess their health, and therefore the highest indicators are detected for the first group, and the lowest indicators - for the third group. However, the highest indicators of internality are identified for the group with chronic diseases. The subjects of this group are largely responsible for their health. The subjects of the second group possess the highest level of anxiety.

Table 3. The indicators of a simple sensorimotor response in the training series

\begin{tabular}{|c|c|c|c|}
\hline \multirow{2}{*}{ Groups } & \multicolumn{3}{|c|}{ Series 0 } \\
\cline { 2 - 4 } & Omissions in the first part & Omissions in the second part & Non-randomness of pressing \\
\hline 1 & $0.7 \pm 0.8$ & $0.5 \pm 0.6$ & $0.67 \pm 0.44$ \\
\hline 2 & $1.9 \pm 3.2^{\star}$ & $1.7 \pm 2.9^{\star}$ & $0.48 \pm 0.51$ \\
\hline 3 & $3.2 \pm 3.7^{\star \star}$ & $2.9 \pm 4.3^{\star \star}$ & $0.40 \pm 0.5^{\star}$ \\
\hline
\end{tabular}

Note: ${ }^{*}$ the differences of data of the corresponding group from the data of the first group with the significance value of $p \leq 0.05 ;{ }^{*}$ - $p \leq 0.01$ (the Wilcoxon test).

The indicators that allow assessing whether a subject could unconsciously discover the fact of iterating the pattern of a signal input, which was called "non-randomness of pressing." Table 3 shows that in the course of insight into the program both in the first and in the second part of the task, more errors were made by the subjects of the third group. They did not manage to detect that the second part of the input of signals completely iterated the first one. The healthy subjects were the first to study in the training series.

However, during the process of complication of the work content, the situation changed (Table 4).

Table 4. The indicators of a simple and complex sensorimotor response in the subjects of three groups

\begin{tabular}{|c|c|c|c|c|c|c|c|c|}
\hline \multirow{2}{*}{ Groups } & \multicolumn{3}{|c|}{ Simple sensorimotor response } & \multicolumn{4}{c|}{ Complex sensorimotor response } \\
\cline { 2 - 9 } & $\begin{array}{c}\text { Omissions } \\
\text { in the part 1 }\end{array}$ & $\begin{array}{c}\text { Omissions } \\
\text { in the part 2 }\end{array}$ & $\begin{array}{c}\text { Non-randomness } \\
\text { of pressing }\end{array}$ & $\begin{array}{c}\text { Omissions } \\
\text { in the part 1 }\end{array}$ & $\begin{array}{c}\text { Omissions } \\
\text { in the part 2 }\end{array}$ & $\begin{array}{c}\text { Non- } \\
\text { randomness of } \\
\text { pressing }\end{array}$ & $\begin{array}{c}\text { Errors in } \\
\text { the part 1 }\end{array}$ & $\begin{array}{c}\text { Errors in } \\
\text { the part 2 }\end{array}$ \\
\hline 1 & $0.2 \pm 0.4$ & $1.0 \pm 1.1$ & $0.47 \pm 0.51$ & $2.3 \pm 2.1$ & $0.9 \pm 0.9$ & $0.60 \pm 0.51$ & $7.3 \pm 2.8$ & $5.8 \pm 1.9$ \\
\hline 2 & $1.1 \pm 1.3$ & $1.4 \pm 2.2$ & $0.65 \pm 0.49^{*}$ & $3.2 \pm 3.3$ & $3.6 \pm 1.4$ & $0.61 \pm 0.50$ & $7.0 \pm 2.8$ & $4.8 \pm 3.0$ \\
\hline 3 & $1.9 \pm 2.7$ & $2.3 \pm 2.9$ & $0.63 \pm 0.49$ & $3.6 \pm 3.4$ & $1.6 \pm 2.3$ & $0.73 \pm 0.45^{*}$ & $6.8 \pm 4.1$ & $5.8 \pm 3.8$ \\
\hline
\end{tabular}

Note: designations as in Table 1.

The table shows that in a simple sensorimotor response, the pattern of a signal input was better predicted by the tested persons of the second group, and in a complex sensorimotor response-by the tested persons of the third group. They made the minimum number of errors where it was necessary to concentrate as much as possible while differentiating the type of signal in a flow. The healthy subjects are easily trained, but quickly lose their potential as far as the task is being complicated, for the performance of which they apparently do not have enough motivation.

A regression analysis also showed that the dependent variable of "non-randomness of pressing in the training series" was influenced by the independent variable of "self-assessment of health" (R2 $=0.402, \beta=0.634, P=0.011)$. The higher the self-assessment of health is, the greater the probability is of that the tested person non-accidentally presses the space bar in the training series, as he realizes that there is a repetition in the input of signals.

It is shown that the dependent variable of "non-randomness of pressing in the training series" is influenced by the independent variable of "self-assessment of health" ( $R 2=0.817, \beta=0.667, P=0.000)$. That is, the higher the probability is of that a person can predict an input of signals, the better the health is according to the self-assessment.

The ability of predicting an input of signals in a simple sensorimotor response was not related to any of the studied parameters.

It is shown that the dependent variable of "non-randomness of pressing in the complex sensorimotor response" is influenced by the independent variable of "anxiety" ( $R 2=0.065, \beta=0.251, P=0.039)$, the coping focused on the avoidance $(R 2=0.063, \beta=0.251, P=0.036)$, the level of general internality $(R 2=0.098, \beta=-0.314, P=0.009)$. It proves once again that these are the tested persons in the third health group, determining the high levels of these characteristics that are the best to realize that the pattern of a signal input in the third series is iterated.

In the third group, the "non-randomness of pressing" in the complex sensorimotor response is related both to the internality in the sphere of health ( $R 2=0.135, \beta=-0.367, P=0.046)$, and to the general internality.

Thus, the data analysis suggests that adaptation to a chronic disease involves, on the one hand, the increase in 
sensitivity to the sensory input apparently not only of the information coming from outside, but also of a similar input of information coming from the organism. A person takes responsibility for his state of health. On the other hand, the person's negative experience of facing a real health care system leads to an increase in the level of emotional coping, and to the establishment of a system of protection against the presence of a severe chronic disease. That is, a person with the described characteristics focuses his activity on those spheres where he feels higher competence.

A person, that experienced the symptoms of a chronic disease for the first time, responses to the new knowledge with increased anxiety, and carefully considers his symptoms, though perhaps it is anxiety that does not allow him to feel the pattern of input of the signals.

A regression analysis detected that the parameter of "hardiness" were not related to the parameter of "nonrandomness of pressing" in any of the series. At the same time, "hardiness" has an effect on the dependent variable of "coping of tasks solving" ( $R 2=0.446, \beta=0.668, P=0.000)$, coping focused on emotions ( $R 2=0.296, \beta=-0.544, P=0.000$ ), anxiety ( $R 2=0.201, \beta=-0.449, P=0.002)$, and self-assessment of health $(R 2=0.179, \beta=0.423, P=0.003)$.

Thus, hardiness, as was expected, is higher in the tested persons of the first group. But only the tested persons of the third health group are the best to realize that the pattern of the input of signals is iterated in the third series.

It can be assumed that hardiness and resilience are the two most important characteristics of a person reflecting different sides of his adaptation to serious circumstances. In one case, a person overcomes the situation due to stressing the resources; in another case, he acquires a new quality (in this case, it is better to predict the sensory input).

Earlier, it was shown (El'nikova, 2014) that healthy tested persons, like the tested persons with chronic diseases, demonstrated an anosognosic type of attitude to a disease, i.e. actively reject the thought of pathology. The healthy tested persons just did not think about the possibility of having a disease, while the chronically ill tested persons, having passed through the domestic health care system, started looking for alternative methods of coping with the disease, primarily referring to the internal resources.

Our data indicate that the tested persons of the third group have acquired the ability to accurately assess the pattern of the signal input in a difficult situation, though the process of their training proceeds a little longer than in the tested persons of the first group who easily master the training series, but do not put much effort to execute a qualitatively complicated version of the experiment. Consequently, these data suggest that in the process of overcoming the problems associated with the occurrence of chronic diseases, the resilience of people, that are aware of the disease and have started looking for the way out from this situation, is objectively enhanced.

An aggregated data analysis indicates that the psychophysiological characteristics can be the effective parameters of the resilience assessment, and that they should be applied in parallel with the psychological tests for greater objectification of the research process.

\section{Acknowledgements}

The study was carried out within the framework of the performance of the base part of the public task of the Ministry of Education and Science of the Russian Federation in 2015.

\section{References}

Endler, D., Norman, S., Parker, \& James, D.A. (1994). Assessment of Multidimensional Coping: Task, Emotion, and Avoidance Strategies. Psychological Assessment, 6(1), 50-60. Retrieved from: http://dx.doi.org/10.1037/1040-3590.6.1.50.

Fetiskin, N.P., Kozlov, V.V., \& Manuilov, G.M. (2002). Sotsial'no-psikhologicheskaia diagnostika razvitiia lichnosti $i$ malykh grupp. Koping-povedenie $v$ stressovykh situatsiiakh [The Sociopsychological Diagnosis of Development of a Personality and Small Groups. Coping Behavior in Stressful Situations] (Norman, S., Endler, D.F., James, D.A., \& Parker, M.I.; version adapted by Kriukova, T.A.) (pp. 442-444). Moscow: Izdatel'stvo Instituta Psikhoterapii [in Russian].

Leont'ev, D.A., \& Rasskazova, E.I. (2006). Test zhiznestoikosti [The test of hardiness] (pp. 63). Moscow: Smysl [in Russian].

Maddi, S., \& Harvey, R. (2005). Hardiness. Considered Across Cultures (pp. 403-420). Handbook of Multicultural Perspectives on Stress and Coping. New York: Springer.

Maddi, S., Harvey, R., Khoshaba, D., Lu, J., Persico, M., \& Brow, M. (2006). The Personality Construct of Hardiness III: Relationships with Repression, Innovativeness, Authoritarianism and Performance. Journal of Personality, 74(32), 575-598.

Ngo-Metzger, Q., Sorkin, D.H., Mangione, C., Gandek, B., \& Hays, R.D. (2008). Evaluating the SF-36 Health Survey (Version 2) in Older Vietnamese Americans. Journal of Aging and Health, 20(4) of June 1, 420-436.

Nikolaeva, E.I., \& Elnikova, O.E. (2014). Attitude to the Diseases of the People with Different Health Levels. Procedia - Social and Behavioral Sciences, 159, 96-100. DOI: 10.1016/j.sbspro.12.336. Retrieved from: http://dx.doi.org/10.1016/j.sbspro.2014.12.336.

Nikolaeva, E.I., Vergunov, E.G., \& Elnikova, O.E. (2015). Model' ustoichivoi adaptatsii khronicheski bol'nykh liudei s ispol'zovaniem variabel'nosti kardioritma [A Model of Sustainable Adaptation of Chronically III People Using the Heart Rate Variability]. 
Sovremennye problemy nauki i obrazovaniia - Contemporary Problems of Science and Education, 1. Retrieved 20.05.2015 from: http://www.science-education.ru/121-19223. DOI: 10.17513/spno.2015.1.121-19223 [in Russian].

Psikhologicheskaia diagnostika otnosheniia k bolezni. Posobie dlia vrachei. [Psychological Diagnostics of Attitude to a Disease. Guide for Physicians.] (2005). St. Petersburg: St. Petersburg V.M. Bekhterev Psychoneurological Research Institute [in Russian].

Ware, J.E., \& Sherbourne, C.D. (1992). The MOS 36-item Short-form Health Survey (SF-36): I. Conceptual Framework and Item Selection. Medical Care, 30, 473-483.

Windle, G., Woods, R.T., \& Markland, D.A. (2010). Living with Ill-health in Older Age: The Role of a Resilient Personality. Journal of Happiness Studies, 11, 763-778. 